\title{
Parapsoriasis Lichenoides
}

National Cancer Institute

\section{Source}

National Cancer Institute. Parapsoriasis Lichenoides. NCI Thesaurus. Code C3920.

A rare condition that stimulated chronic radiodermatitis. It is considered a variant of mycosis fungoides. 